\title{
Characterization of Breast Meat Collected from Spent Lohmann Brown Layers in Comparison to Commercial Ross Broilers
}

-Author(s)

Limpisophon K' (iD https://orcid.org/0000-0001-5435-4902 E-tun S' (D) https://orcid.org/0000-0002-2664-0968 Koeipudsa C' (ID) https://orcid.org/0000-0002-8479-1086 Charoensuk D" (iD) https://orcid.org/0000-0002-4884-4160 Malila Y" (D) https://orcid.org/0000-0001-5950-5319

Department of Food Science and Technology, Faculty of Agro-Industry, Kasetsart University, 50 Ngamwongwan Rd., Chatuchak, Bangkok, 0900, Thailand.

National Center for Genetic Engineering and Biotechnology (BIOTEC), 113 Thailand Science Park, Phahonyothin Rd., Khlong Nueng, Khlong Luang, Pathum Thani, 12120, Thailand.

\section{Mail Address}

Corresponding author e-mail address Yuwares Malila

113 Phahonyothin Rd., Khlong Neung, Khlong Luang, Pathum Thani, 12120, Thailand

Phone: +662.117.8031

Email: yuwares.mal@biotec.or.th

\section{- Keywords}

Muscle fiber, physicochemical properties, protein fractionation, technological properties, thermal properties.

\section{ABSTRACT}

The objective of this study was to compare characteristics and properties of breast meat from spent Lohmann Brown layers (SP, 90 weeks old, $\mathrm{n}=24$ ) and those of commercial broilers (BR, 6 weeks old, $n=24)$. The breasts of both SP and BR were collected from a local processing plant, vacuum-packed in a plastic bag, and stored at $-18^{\circ} \mathrm{C}$ until further analyses. The SP showed a greater water-holding capacity, tougher and chewier texture $(p<0.05)$. Both raw and cooked SP breasts comprised the greater total collagen but lower soluble collagen than those of BR $(p<0.05)$. Muscle fibers of the SP, observed under scanning electron microscope, were small, with average fiber diameter of $37.85 \pm 1.40 \mu \mathrm{m}$, densely packed and surrounded by complex networks of connective tissue. The lower myofibril fragmentation index and alkaline-soluble protein fractions of the SP $(p<0.05)$ suggested lesser degree of postmortem fragmentation and protein denaturation in SP compared to BR. Based on differential scanning calorimetry, multiple endothermic transitions were observed in both raw BR and SP breast samples. While $\mathrm{BR}$ thermograms comprise five transitions at $57.7^{\circ} \mathrm{C}$, $64.2^{\circ} \mathrm{C}, 67.6^{\circ} \mathrm{C}, 72.3^{\circ} \mathrm{C}$ and $77.6^{\circ} \mathrm{C}$ with total $\Delta \mathrm{H}$ of $15.31 \mathrm{~J} / \mathrm{g}$ dry meat, the SP samples exhibited four transitions at $55.1^{\circ} \mathrm{C}, 62.1^{\circ} \mathrm{C}, 70.5^{\circ} \mathrm{C}$ and $77.7^{\circ} \mathrm{C}$ and total $\Delta \mathrm{H}$ of $17.62 \mathrm{~J} / \mathrm{g}$ dry meat. Overall, the findings indicated that cooked meat toughness of SP was attributed by the high total and heat-stable collagen content, densely packing of small muscle fibers, and the superior myofibril integrity.

\section{INTRODUCTION}

The spent laying hens are the massive by-products of the poultry industry. Although the meat is inexpensive and nutritious (Suriani et al., 2014; Lakshani et al., 2016), it has been underutilized for human consumption due mainly to its undesirable tough texture. As the hens are spent at considerably long age (approximately 90 weeks), their meat comprises heat-stable cross-linked connective tissues which required an extreme cooking condition to be degraded (Fletcher, 2002). In addition to the prolonged slaughter age, commercial layers have been selectively bred with an emphasis only on egg quality and production efficiency. The hens are relatively small in size in order to minimize energy requirement and feed consumption. Those two factors, age and genetics, certainly manifest muscle composition and arrangement within the spent hen meat, which in turn affect eating quality of its meat (Tang et al. 2009; Chen et al., 2016).

Previous studies demonstrated plausible applications of the meat as raw materials for canned products (Chuaynukool et al., 2007) or for comminuted products (Jin et al., 2007; Sorapukdee et al., 2016). Still, the use of the whole muscle, i.e. whole breast or drumstick, has been of interest for poultry industry. Development of tenderization approach of 
which the meat is still in the intact form, however, has been a great challenge. Several attempts have been addressed in order to improve tenderness of spent layer meat mostly using enzymes (DeVitre \& Cunningham, 1985; Kang et al., 2012) or using marinade treatments with salt and phosphate solutions (Chueachuaychoo et al., 2011). Alteration of collagen thermal stability, with an attempt to tenderize spent hen meat, was also demonstrated in the study of Sams (1990) in which layers (72 weeks of age) were fed with diets containing $0.18 \% \quad \beta$-aminopropionitrile (BAPN), a nucleophilic compound inhibiting formation of collagen cross linking, up to 64 days prior to slaughter. Although increased collagen solubility was found in the BAPNtreated samples, the shear force values of the treated samples did not differ from those of the control. Advanced technology, such as high-pressure process, has offered alternative method for meat tenderization. Nonetheless, an effective feasible technique for the industry has not been successfully developed.

Lohmann Browns are one of the commercial layers that provide large brown-shell eggs. Originally developed in Germany, the birds have been widely used in the egg industry as the birds begin to lay eggs at 14 weeks of age which is earlier than other layers and provide high egg productivity. Similar to other breeds, at the end of the laying cycles, the most spent Lohmann Brown hens are used as low-priced animal feed. The idea of producing whole-muscle processed food productions from the spent Lohmann hens are also of interest, yet a challenge as some characteristics of the spent Lohmann hens muscle fiber that has not been revealed. Characterization of the spent Lohmann breast meat in accompanied with those consumer-accepted meat of broilers might offer additional comprehension which could lay foundation in improvement of meat tenderness of both spent Lohmann and the others. The objective of this study was to investigate technological quality, physicochemical and thermal properties as well as muscle fiber of breast meat between spent commercial Lohmann Brown layers (90 weeks of age) in comparison to the meat collected from commercial Ross 308 broilers ( 6 weeks of age), one of the most raised and consumed broilers.

\section{MATERIALS AND METHODS}

\section{Samples and sample collection}

Twenty-four breasts of commercial Ross 308 broilers ( 6 weeks of age) and twenty-four breasts of Lohmann Brown layers ( 90 weeks of age), representing commercial broilers (BR) and spent commercial laying hens (SP), respectively, were used in this study. All samples were purchased from the commercial processing plant without either experimental treatments or scientific procedures directly subjected to the living animals. In this regards, according to BIOTEC Institutional Animal Care and Use Committee, the ethical approval was not required.

All chickens were raised and processed due to the routine standard practice of a local industrial abattoir (Saraburi, Thailand).The detail of the processing includes the fasting for $12 \mathrm{~h}$ followed by the manual neck cutting, 3-min bleeding, scalding at $70^{\circ} \mathrm{C}$ for $2 \mathrm{~min}$, plucking in a rotary drum for $30 \mathrm{~s}$, and advanced to an evisceration. The eviscerated carcass was chilled using water immersion method at approximately $0.6^{\circ} \mathrm{C}$ for 75 min, and subsequently cut and deboned. Visible skin, extra fat and connective tissue were trimmed from the breast samples. At the end of the processing line, the sample was randomly collected, individually vacuumpacked in a plastic bag and stored at $-18^{\circ} \mathrm{C}$ for $6 \mathrm{~h}$. The frozen meat was stored on ice while transported back to Food Biotechnology Laboratory, BIOTEC (Pathum Thani, Thailand). Upon arrival, the samples were stored at $-20^{\circ} \mathrm{C}$ until further analyses. Prior to any experiment, the meat was thawed overnight at $4^{\circ} \mathrm{C}$.

Of twenty-four, five breasts were subjected for determination of moisture, $\mathrm{pH}$, myofibril fragmentation index (MFI), collagen, and protein fractionation. Ten pieces of the breast meat were for water-holding capacity $(\mathrm{WHC})$ and texture analyses. The other five were for evaluation of microscopic images, leaving the other four for thermal properties.

\section{Moisture content and pH}

Moisture of raw and cooked samples were evaluated according to AOAC (2000). The $\mathrm{pH}$ of raw meat was measured by directly inserting a spear-shape electrode coupled to a pH meter (model Seven Easy, MettlerToledo, Switzerland) into the meat.

\section{Myofibril fragmentation index}

The value of MFI was determined as described by Hopkins et al. (2000). In brief, $0.5 \mathrm{~g}$ of chopped raw meat sample was homogenized, on ice, with $30 \mathrm{ml}$ of ice-cold MFI buffer ( $25 \mathrm{mM}$ potassium phosphate buffer, pH 7.0 containing $0.1 \mathrm{M} \mathrm{KCl}, 1 \mathrm{mM}$ EDTA and $1 \mathrm{mM}$ sodium azide) at 13,500 rpm for $2 \mathrm{~min}$ (30 sec on followed by $30 \mathrm{sec}$ rest, 2 cycles). The homogenate was filtered through two layers of gauzes and rinsed with $10 \mathrm{ml}$ cold MFI buffer. The filtrate 
was subsequently centrifuged at $1,000 \times g$ for $10 \mathrm{~min}$ at $2^{\circ} \mathrm{C}$. The resulting pellets of myofibrils were resuspended in $10 \mathrm{ml}$ of cold MFI buffer. The extraction was repeated twice and the pellet was finally resuspended in $10 \mathrm{ml}$ of cold MFI buffer. The protein concentration of the suspensions was determined using the Pierce Bicinchoninic acid (BCA) Protein Assay kit (Thermo Scientific, Rockford, Illinois, USA) following manufacturer's recommendation. Absorbance of the diluted myofibril suspensions, diluted in MFI buffer to a final protein concentration of $0.5 \mathrm{mg} / \mathrm{ml}$ with a total volume of $2 \mathrm{ml}$, was determined at $540 \mathrm{~nm}$ using MFI buffer as blank. MFI was calculated by multiplying the average absorbance with 200.

\section{Water-holding capacity (WHC)}

Herein, drip loss, cooking loss and expressible water were used as indicators of WHC and determined consecutively in each breast sample as previously addressed (U-chupaj et al., 2017). Briefly, each breast meat was weighed and subsequently packed in a plastic bag and hung at $4^{\circ} \mathrm{C}$ for $24 \mathrm{~h}$. Drip loss was calculated as a percentage of weight loss relative to initial weight of the meat after it was hung at $4^{\circ} \mathrm{C}$ for $24 \mathrm{~h}$. Afterwards, the sample was individually repacked in a plastic bag and cooked at $95^{\circ} \mathrm{C}$ by water immersion until internal temperature of the thickest part of the sample, monitored using a thermocouple, reached $85^{\circ} \mathrm{C}$ (U-chupaj et al., 2017). After cooling in ice-cold water until the core temperature reached $10^{\circ} \mathrm{C}$, the meat was rested for $2 \mathrm{~h}$ at $4^{\circ} \mathrm{C}$, then removed from the bag, blotted dry and reweighed. Cooking loss was expressed as a percentage of weight loss after cooking. Each cooked breast was cut parallel to muscle fiber alignment into two cubes $(1 \mathrm{~cm} \times 1$ $\mathrm{cm} \times 1 \mathrm{~cm})$ and one rectangular cuboid $(10 \mathrm{~mm} \times$ $15 \mathrm{~mm} \times 10 \mathrm{~mm}$ ). While one of the cubes and the cuboid were used in the texture analysis (described in the following section), the other prepared cube was weighed, placed between two sheets of Whatman filter paper and subjected to a compression at $70 \%$ strain under a force of $50 \mathrm{~g}$ for 60 seconds using a TA-XT2i texture analyzer (Stable Micro Systems, Godalming, UK) equipped with a 50-mm aluminum cylinder probe. Apparent expressible water and expressible water of each sample were calculated as follows.

Initial weight (g) - Final weight (g)

Apparent expressible water $(\%)=100 \times \frac{\text { Initial weight }(\mathrm{g})}{}$

$$
\text { Expressible water }(\%)=100 \times \frac{\text { Apparent expressible water }(\%)}{\text { Moisture content of sample }(\%)}
$$

\section{Texture analysis}

Texture of the cooked samples was evaluated following Warner-Bratzler shear test and texture profile analysis (TPA) using a TA-XT2i texture analyzer (U-chupaj et al., 2017). The samples, subjected to the WBS and TPA, were the cooked breast samples prepared into the rectangular cuboids and the cubes, respectively, as mentioned above. All textural parameters were automatically calculated by Texture Expert version 1.0 software (Stable Micro Systems). The operational condition for WBS test was set as follows; crosshead speed $1 \mathrm{~mm} / \mathrm{s}$, working distance 25 to 30 $\mathrm{mm}$, and trigger force 0.2 N.As for TPA, the operating parameters consisted of a double compression cycle with test speed $1 \mathrm{~mm} / \mathrm{sec}$, holding time $1 \mathrm{sec}$, working distance 30\% strain, surface sensing force $99 \mathrm{~g}$, threshold $30 \mathrm{~g}$ and time interval between the first and the second stroke $1 \mathrm{sec}$.

\section{Total collagen content and soluble collagen}

Total collagen content and soluble collagen was determined after acid hydrolysis as described by Kittiphattanabawon et al (2010) with a modification. Briefly, for total collagen, $0.5 \mathrm{~g}$ of chopped raw and cooked samples was hydrolyzed with $5 \mathrm{ml}$ of $6 \mathrm{~N}$ $\mathrm{HCl}$ at $110^{\circ} \mathrm{C}$ for $24 \mathrm{~h}$. The neutralized hydrolysate $(\mathrm{pH} 7.0 \pm 0.05)$ was filtered and diluted with distilled water to a final volume of $50 \mathrm{ml}$. Ten microliters of the hydrolysate or hydroxyproline standard was reacted with $10 \mu \mathrm{l}$ of oxidizing reagent (one volume of $7 \% \mathrm{~W} / \mathrm{V}$ of chloramin $\mathrm{T}$ in aqueous solution and four volumes of $1 \mathrm{M}$ acetate/citrate buffer, $\mathrm{pH}$ 6.0), $20 \mu \mathrm{l}$ of isopropanol and $139 \mu \mathrm{l}$ of Ehrlich's reagent. After incubation at $60^{\circ} \mathrm{C}$ for $25 \mathrm{~min}$, absorbance at $558 \mathrm{~nm}$ of the mixture was measured. Concentration of hydroxyproline was converted to collagen content using the factor of 7.25. For soluble collagen, $7 \mathrm{~g}$ of either raw or cooked meat was homogenized with 28 $\mathrm{ml}$ of $25 \%$ Ringer's solution. The homogenate was then heated at $77^{\circ} \mathrm{C}$ for 70 min and centrifuged for $30 \mathrm{~min}$ at $1600 \times \mathrm{g}, 4^{\circ} \mathrm{C}$. The resulting supernatant was collected and hydrolyzed with 10 volumes of $6 \mathrm{~N} \mathrm{HCl}$ at $110^{\circ} \mathrm{C}$ for $24 \mathrm{~h}$. Soluble collagen content was then determined as stated in the protocol for total collagen determination. All measurements were done in triplicates. The amount of total collagen and soluble collagen were expressed as milligrams of collagen per gram of dry meat. Collagen solubility was calculated as follow. 
Soluble collagen $\left(\frac{m g}{g}\right.$ dry meat $) \times 100$

Collagen solubility $(\%)=$

Total collagen (mg $\frac{\vdots}{\vdots \vdots}$ : $g$ dry meat)

\section{Microstructure}

Microstructure of raw chicken breast $(n=5)$ was observed under a scanning electron microscopy (SEM). The sample $(1 \mathrm{~cm} \times 1 \mathrm{~cm} \times 0.5 \mathrm{~cm})$ was fixed in $2.5 \%$ glutaraldehyde in $0.1 \mathrm{M}$ phosphate buffer and dehydrated in ethanol solution with a serial concentration of $25 \%, 50 \%, 75 \%, 95 \%$ and $100 \%$. Microscopic views of the dried specimen, sputtercoated with gold, were observed at 70x and 1,000x magnification under a field-emission SEM (model SU5000, Hitachi, Hitachi Europe Ltd., Germany) using an acceleration voltage of $10 \mathrm{kV}$. The microscopic images were processed using ImageJ software. The fiber density was estimated by counting total fiber number (TFN) in nine 70x fields per specimen (modified from Alves et al., 2012). The average fiber diameter was calculated from the mean cross-sectional area of the fiber, which was obtained by dividing total crosssectional fiber area with TFN within each field.

\section{Protein fractionation}

Protein components of BR and SP breast meat were fractionated (Visessanguan et al., 2004). All steps were conducted at $4^{\circ} \mathrm{C}$. Three grams of choppedraw meat samples were homogenized with ten volumes of phosphate buffer ( $\mathrm{pH} 7.5)$, containing $15.6 \mathrm{mM}$ $\mathrm{Na}_{2} \mathrm{HPO}_{4}$ and $3.5 \mathrm{mM} \mathrm{KH_{2 }} \mathrm{PO}_{4}$, at 9,500 rpm for 1 min. After centrifugation at 5,000×g for 15 min, the pellet was discarded. The supernatant was mixed with cold $50 \%$ trichloroacetic acid to a final concentration of $10 \%$ and re-centrifuged at $5000 \times \mathrm{g}$ for $15 \mathrm{~min}$. The resulting pellet from the second centrifugation was collected as a water-soluble fraction while the supernatant was labeled as a non-protein nitrogen (NPN). The pellet was then extracted with ten volumes of phosphate buffer (pH 7.5), containing $0.45 \mathrm{M} \mathrm{KCl}$ at 9,500 rpm for $1 \mathrm{~min}$ and centrifuged at $5000 \times \mathrm{g}$ for $15 \mathrm{~min}$. The supernatant was classified as a saltsoluble fraction. The obtained pellet was continuously stirred with ten volumes of $0.1 \mathrm{M} \mathrm{NaOH}$ for $4 \mathrm{~h}$, and subjected to centrifugation at $5000 \times \mathrm{g}$ for $15 \mathrm{~min}$. The supernatant and the residue were alkali-soluble and alkali-insoluble fractions, respectively. The nitrogen content of all fractions was determined using the Kjeldahl method (AOAC, 2000).

\section{Thermal properties}

Thermal properties of the raw chicken breast meat were evaluated using a differential scanning calorimeter (DSC) model 822E (Mettler-Toledo GmbH, Switzerland) according to the method of Visessanguan et al. (2000). In brief, approximately $12 \mathrm{mg}$ of chopped raw breast samples were hermetically sealed in a $40-\mu$ l aluminum DSC pan. Thermal transitions of the samples were monitored during heating the samples from $25^{\circ} \mathrm{C}$ to $105^{\circ} \mathrm{C}$ at a scanning rate of $5^{\circ} \mathrm{C} / \mathrm{min}$. An empty DSC pan was used as a reference. Onset temperature $\left(T_{\text {onset }}\right)$, peak temperature $\left(T_{\text {peak }}\right)$, final temperature $\left(T_{\text {final }}\right)$ and enthalpy $(\Delta \mathrm{H})$ were analyzed using the STARe Thermal Analysis software 14.00. The value of $\Delta T$, the difference between $\mathrm{T}_{\text {final }}$ and $\mathrm{T}_{\text {onset' }}$ for each transition was subsequently calculated. The measurements were carried out on four replicates and reported as the average.

\section{Statistical analysis}

Statistical analysis was conducted using $\mathrm{R}$ version 3.2.1 (Mangiafico, 2015). Independent t-tests were carried out to compare the means between SP and $\mathrm{BR}$ samples. The additional independent t-tests were also performed to evaluate the effects of cooking on collagen contents and collagen solubility within the group of SP and BR samples. The significant level for all analyses was set at $\alpha=0.05$.

\section{RESULTS}

Physicochemical properties and technological qualities of BR and SP breast meat samples are shown in Table 1. The SP samples exhibited lower moisture in raw meat but greater moisture in cooked samples compared to those of $\mathrm{BR}(p<0.05)$. The values of $\mathrm{pH}$ and MFI of SP breasts were also lower than those of BR. Drip loss, cooking loss and expressible water of the SP were lower than those of the BR $(p<0.05)$, indicating superior WHC of the SP samples over the BR ones. Despite no differences in hardness and springiness, the greater values of shear force, shear energy, cohesiveness and chewiness of the SP were detected $(p<0.05)$. The current WBS and TPA data supported the tougher and chewier textural characteristics of the cooked SP breast meat in comparison to those of the BR. 
Table 1 - Technological quality of breast meat collected from commercial broilers (BR) and spent Lohmann Brown layers (SP) ${ }^{1}$

\begin{tabular}{|c|c|c|c|}
\hline Properties & $\mathrm{BR}$ & SP & Significant difference $^{2}$ \\
\hline \multicolumn{4}{|l|}{ Moisture content (\%) } \\
\hline Raw meat & $75.36 \pm 0.49$ & $74.45 \pm 0.30$ & * \\
\hline Cooked meat & $64.42 \pm 0.10$ & $68.58 \pm 0.30$ & * \\
\hline $\mathrm{pH}$ & $6.01 \pm 0.13$ & $5.85 \pm 0.03$ & * \\
\hline Myofibril fragmentation index (MFI) & $19.89 \pm 1.74$ & $5.71 \pm 3.36$ & * \\
\hline \multicolumn{4}{|l|}{ Water-holding capacity } \\
\hline Drip loss (\%) & $2.81 \pm 0.35$ & $1.99 \pm 0.19$ & * \\
\hline Cooking loss (\%) & $7.70 \pm 1.49$ & $3.75 \pm 0.31$ & * \\
\hline Expressible water (\%) & $24.33 \pm 0.63$ & $22.57 \pm 0.78$ & * \\
\hline \multicolumn{4}{|l|}{ Textural characteristics of cooked meat } \\
\hline Shear force $(\mathrm{N})$ & $39.64 \pm 7.49$ & $65.47 \pm 7.77$ & * \\
\hline Shear energy (N.S) & $307.18 \pm 46.61$ & $519.85 \pm 52.93$ & * \\
\hline Hardness (N) & $23.35 \pm 0.91$ & $26.43 \pm 6.41$ & NS \\
\hline Springiness & $0.63 \pm 0.05$ & $0.65 \pm 0.02$ & NS \\
\hline Cohesiveness & $0.34 \pm 0.01$ & $0.46 \pm 0.01$ & * \\
\hline Chewiness $(\mathrm{N})$ & $5.07 \pm 0.45$ & $7.91 \pm 2.26$ & * \\
\hline
\end{tabular}

'Data are presented as mean \pm standard deviation, where $n=5$ for physicochemical property determination and $n=10$ for analyses of water-holding capacity and texture. $2^{*} p<0.05$, NS $=$ not significant $(p \geq 0.05)$

Considering collagen content in the breast samples (Table 2), the SP samples composed of a significantly greater total collagen. Additionally, collagen networks of the SP increased in thermal stability as reflected by the lower soluble collagen content and collagen solubility $(p<0.05)$. Once cooked, collagen in both cooked SP and BR samples could be solubilized to the greater extent $(p<0.05)$, indicating the breakdown of collagen networks in both samples during cooking. Still, solubility of the collagen in the SP was lower than that of the BR $(p<0.05)$.

Table 2 - Collagen content of breast meat collected from commercial broilers (BR) and spent Lohmann Brown layers (SP) ${ }^{1,2}$

\begin{tabular}{|c|c|c|c|c|c|c|}
\hline \multirow[t]{2}{*}{ Chicken } & \multicolumn{2}{|c|}{$\begin{array}{l}\text { Total collagen } \\
\text { (mg/g dry meat) }\end{array}$} & \multicolumn{2}{|c|}{$\begin{array}{l}\text { Soluble collagen } \\
\text { (mg/g dry meat) }\end{array}$} & \multicolumn{2}{|c|}{$\begin{array}{c}\text { Collagen solubility } \\
(\%)\end{array}$} \\
\hline & Raw meat & Cooked meat & Raw meat & Cooked meat & Raw meat & Cooked meat \\
\hline$B R$ & $16.43 b \pm 3.02$ & $10.96 \mathrm{a} \pm 2.02$ & $3.24 a \pm 1.15$ & $7.60 b \pm 4.55$ & $19.72 a \pm 5.98$ & $58.88 b \pm 24.54$ \\
\hline SP & $34.82 a \pm 19.13$ & $39.68 a \pm 10.96$ & $2.14 a \pm 0.71$ & $3.44 b \pm 0.93$ & $7.52 a \pm 3.38$ & $12.07 b \pm 2.74$ \\
\hline Significant difference ${ }^{3}$ & * & $\star \star$ & * & * & ** & ** \\
\hline
\end{tabular}

'Data are presented as mean \pm standard deviation, where $n=5$. ${ }^{2}$ Different letters indicate significant difference $(p<0.05)$ of the same collagen type between raw and cooked breast samples within the same row. ${ }^{3 *} p<0.05,{ }^{* *} p<0.001$ within the same column.

Cross sections of muscle fibers from the SP and BR were observed under SEM (Figure 1). The average fiber diameters of the SP and BR were $37.85 \pm 1.40 \mu \mathrm{m}$ and $42.18 \pm 2.35$ $\mu \mathrm{m}$, respectively. Not only were the SP fibers smaller, the SP fibers were more densely packed (304 \pm 55 fibers per $\left.\mathrm{mm}^{2}\right)$ than those of the BR $\left(223 \pm 68\right.$ fibers per $\left.\mathrm{mm}^{2}\right)(p<0.05)$ and apparently surrounded by connective tissue (Figure 1c, d).

Proteins of the breast samples were fractionated based on their solubility into five fractions, including NPN, water-soluble, saltsoluble, alkali-soluble and alkali-insoluble fraction (Figure 2). Interestingly, the alkalisoluble fraction, representing collagen and the denatured myofibrillar proteins
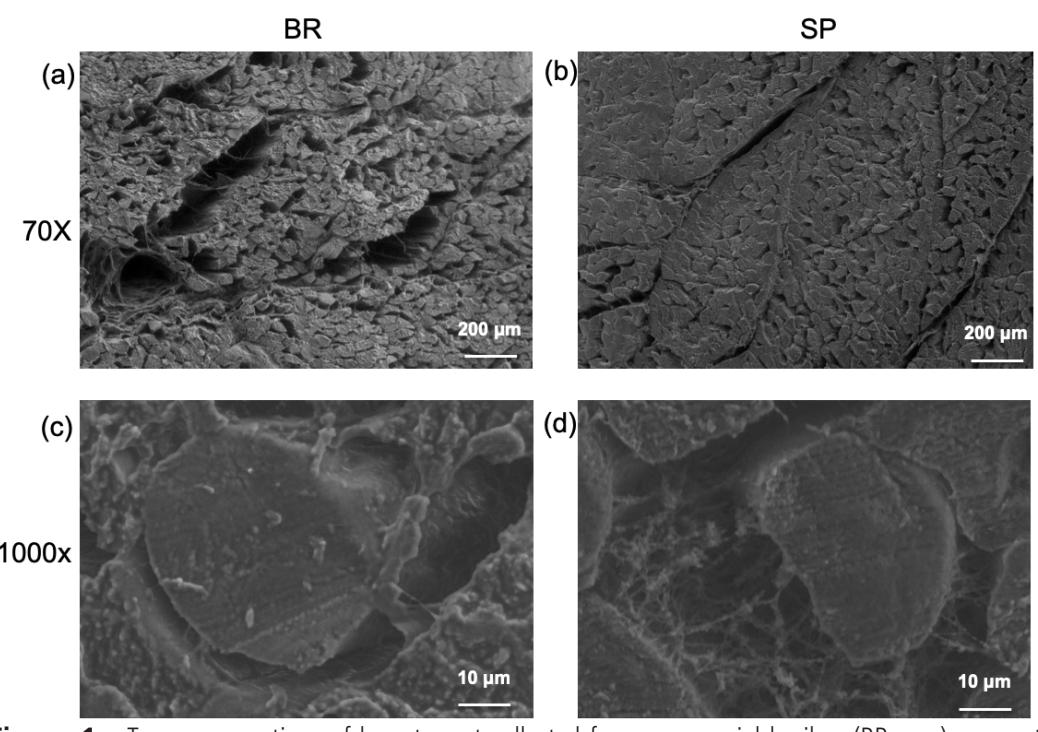

Figure 1 - Transverse sections of breast meat collected from commercial broilers (BR; $a, c)$ or spent Lohmann Brown layers (SP; b, d) observed under scanning electron microscope with magnification of $70 \mathrm{x}$ $(\mathrm{a}, \mathrm{b})$ or $1000 \mathrm{x}(\mathrm{c}, \mathrm{d})$. 
(Visessanugan et al., 2004), was the main fraction of both samples. The particular fraction was more pronounced in BR compared to that of SP $(p<0.05)$. Besides, the NPN fraction highly varied among the BR samples. The results suggested that the meat proteins in the BR has been undergone denaturation and degradation to the greater extent.

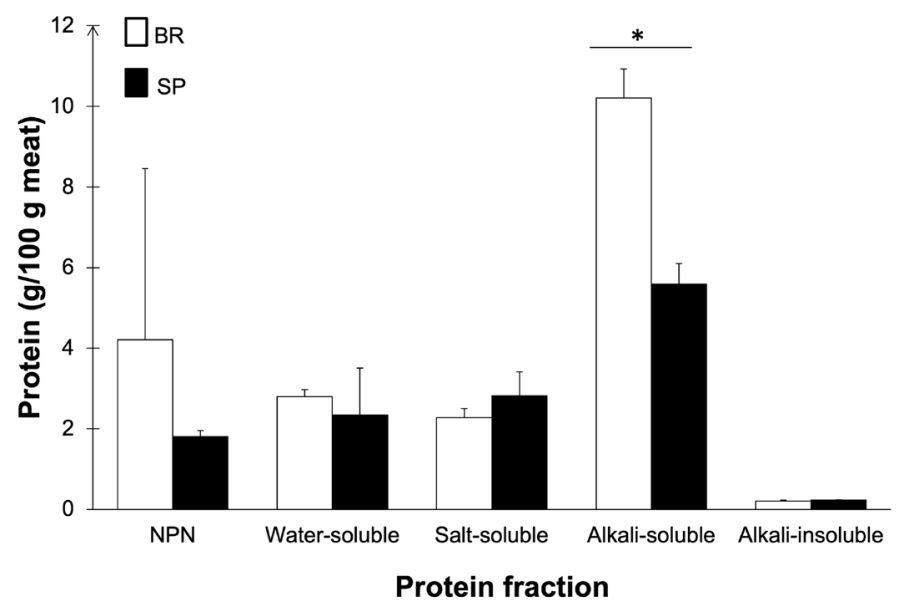

Figure $\mathbf{2}$ - Protein fractionation in breast samples $(n=5)$ of commercial broilers (BR) and spent Lohmann Brown layers (SP). Bars and error bars illustrate mean and standard deviation, respectively. NPN = non-protein nitrogen. Asterisk indicates statistical difference between chicken types $(p<0.05)$.

Focusing on DSC thermograms (Figure 3), broad endothermal transitions were present in both raw $B R$ or SP breast samples. Thermograms of the BR samples comprise five thermal transitions, occurring at around $57.7^{\circ} \mathrm{C}, 64.2^{\circ} \mathrm{C}, 67.6^{\circ} \mathrm{C}, 72.3^{\circ} \mathrm{C}$ and $77.6^{\circ} \mathrm{C}$ with total $\Delta \mathrm{H}$ of $15.31 \mathrm{~J} / \mathrm{g}$ dry meat (Table 3). For the SP samples, the overall thermal profile shifted towards lower temperature with four apparent transitions at $55.1^{\circ} \mathrm{C}$, $62.1^{\circ} \mathrm{C}, 70.5^{\circ} \mathrm{C}$ and $77.7^{\circ} \mathrm{C}$ and total $\Delta \mathrm{H}$ of $17.62 \mathrm{~J} / \mathrm{g}$ dry meat. The third transition was more likely merged with the second peak. The declined $T_{\text {onset }}$ and $T_{\text {peak }}$ of SP in comparison to those of BR were significant in peak 1 and peak $2(p<0.05)$. Additionally, in the second transition, although $\mathrm{T}_{\text {onset }}$ and $\mathrm{T}_{\text {peak }}$ were significantly lower in the SP, the endothermic event underwent to the greater extent in the SP samples, leading to the significant increased $\Delta \mathrm{T}(p<0.05)$. In term of energy required for the thermal transitions, SP samples showed significantly less $\Delta \mathrm{H}$ in the first transition but greater $\Delta \mathrm{H}$ values in the second and fifth transitions compared to those of $\mathrm{BR}(p<0.05)$.

\section{DISCUSSION}

Many aspects influence overall meat quality. Between broilers and spent layers, differences in breeding purposes and animal age are among those key players. It is worth noting that a direct comparison

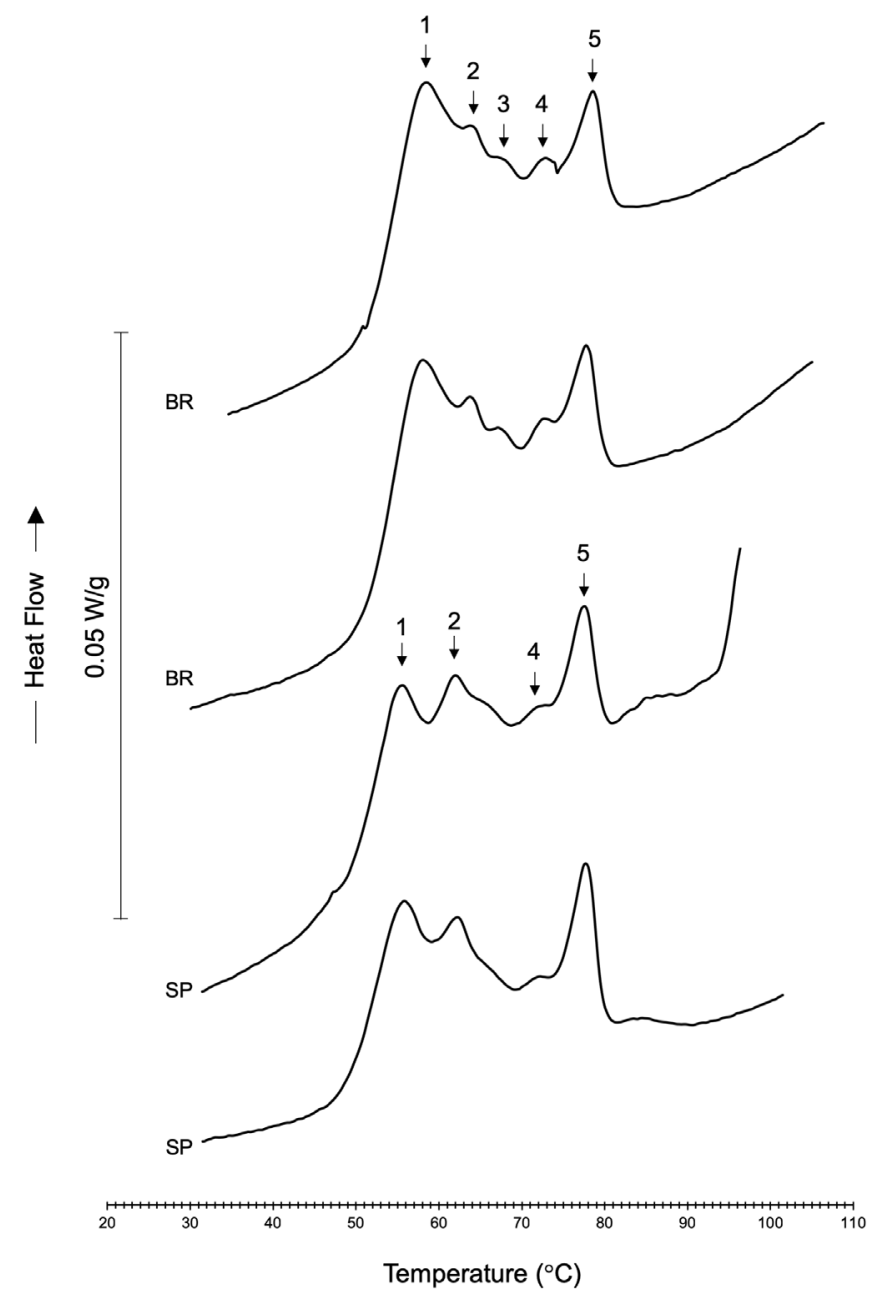

Figure 3 - Thermograms of breast meat collected from commercial broilers ( $B R, n=4)$ and spent Lohmann Brown hens $(S P, n=4)$. The arrows and numbers indicate the endothermic transitions observed in each sample.

of overall meat quality between BR and SP is more likely confounded by those combined with other different extrinsic factors, i.e. feeding regime and rearing management. However, in this study, the used BR samples were initially aimed to be benchmark in determination of the SP muscle fibers. Ultimately, by characterizing the BR alongside, it has become clearer which aspects of the SP fibers that can be modified to improve the tenderness of the cooked SP meat.

The tougher and chewier texture of the cooked spent Lohmann Brown breast meat in comparison to those of the commercial Ross 308 were as expected. The current observation was consistent with the previous experiment of Dawson et al. (1991) in which texture of cooked meat of spent Leghorn hens (20 to 24 months of age) and broilers ( 6 to 7 weeks of age) were compared. Tang et al. (2009) also reported that cooked breast meat of two commercial broiler lines, Avian (7 weeks of age) and Lingnanhuang (8 weeks of age), required lower force to cut through 
Table 3 - Thermal parameters of breast meat collected from commercial broilers (BR) and spent Lohmann layers (SP) $)^{1,2}$

\begin{tabular}{lccccccccc}
\hline & Parameter & & BR & & & SP & & p-value & Significant \\
difference
\end{tabular}

'Data are presented as mean \pm standard deviation, where $n=4$.

${ }^{2}$ n.a. $=$ not applicable.

${ }^{3 *} p<0.05,{ }^{* *} p<0.01,{ }^{* *} p<0.001, \mathrm{NS}=$ not significant $(p \geq 0.05)$

in comparison to 16-week-old Hy-Line Brown layers. Similar observation was documented in the study of An et al. (2010) in which meat quality indices and muscle characteristics of broilers ( 6 weeks of age) and White Leghorn chickens ( 6 and 18 weeks of age) were examined. The cooked breast meat of 18-week-old White Leghorn exhibited the greatest shear force and shear energy. Recently, Chen et al. (2016) compared technological properties of the meat collected from 560-day-old (approximately 74 weeks) Hy-Line Brown layers and those of 40-day-old (nearly 6 weeks) Acres broilers and reported a comparable trend.

Texture of cooked meat depends mainly upon muscle composition, muscle fiber size and arrangement, as well as postmortem biochemical events in the muscle (Fletcher, 2002; An et al., 2010).Considering muscle fiber of spent Lohmann breast, the current findings were in accordance with numbers of previous studies (Cooke et al., 2003; Koomkrong et al., 2015; Buzala \& Janicki, 2016). The smaller fibers in the SP samples occupied less space, resulting in the densely packed fibers in comparison to that in the BR samples. The difference in muscle fiber size and density has obviously been the consequences of breeding selection for divergent purposes of those two chicken lines.
Influences of muscle fiber size and density on meat tenderness have been previously discussed. Mutungi et al. (1996) investigated the effects of muscle fiber size (diameter below or above $60 \mu \mathrm{m}$ ) on force required to fracture the porcine longissimus muscle and reported the less force to fracture the fibers having diameter larger than $60 \mu \mathrm{m}$. Later, Johnston et al., (2000) found significant positive correlations between muscle fiber density and chewiness as well as firmness of cooked meat of Atlantic salmon. On the contrary, the increased meat toughness associated with small muscle fiber diameter was previously investigated in caponized and indigenous chickens. Lin \& Hsu (2002) reported a significantly smaller muscle fiber diameter as well as a greater toughness in caponized chicken breast meat compared to that of normal cockerels $(p<0.05)$. In Thai indigenous chicken, the diameter of all muscle fiber types was smaller compared with the imported meat-type breeds (Jaturasitha et al., 2008). An et al. (2010) found a significantly negative correlation between shear force and muscle fiber density when myofibers of White Leghorns (6-week-old, 18-weekold) and broilers (6-week-old) were compared. The discrepancies were suggested to be the impact of muscle membrane combined with different fiber sizes 
(An et al., 2010). Besides of the previous explanation, the inconsistent trend regarding the myofiber size and density on texture of the cooked meat could be due to the influences of divergent composition and maturity of endomysium and perimysium among species and animals (An et al., 2010).

Apart from muscle fiber, connective tissue has been considered as the background contributor to meat texture (Purslow, 2005). As animals advance in age, stability of the collagen fibers increased theoretically through covalent cross-links within or between collagen molecules (Smith-Mungo \& Kagan, 1998). Highly cross-linked collagen networks exhibited stability to thermal denaturation as well as tensile strength of the collagen networks (Snedeker \& Gautieri, 2014); as a result, it reduced tenderness of the meat as currently observed in the SP breast samples collected from spent Lohmann Brown fowls. In addition to the superior collagen thermal stability, total collagen contents of the raw and cooked SP samples were greater than that of the BR. The findings herein corresponded to the previous studies revealing the tendency of decreased collagen content in poultry meat in accordance with breeding selection for fast-growing meat-type birds (Sirri et al., 2011; Funaro et al., 2014; Chen et al., 2016). As illustrated in the present SEM micrographs, the interspaces between the SP fiber bundles were markedly occupied by thick networks of connective tissues. In the study of An et al. (2010), the markedly thicker perimysium, mainly consisting of collagen, was observed in the breast muscle of 18-week-old White Leghorns compared to those of 6-week-old White Leghorns and broilers.

In addition to collagen content, the amounts of water retained within cooked meat influenced its tenderness and mouthfeel (Tyszkiewicz et al., 1997). As observed herein, the cooked SP samples contained higher moisture than cooked BR. The greater juiciness of the SP could be implicated but the impact of water content might not be sufficient to overcome the effects of structure of muscle fiber combined with collagen stability.

Another key determinant of ultimate meat tenderness is the postmortem biochemical events within the muscle. Anaerobic glycolysis, the major metabolic process responsible for ATP production at the early postmortem stage, led to accumulation of lactic acid, lowering muscle $\mathrm{pH}$ to ultimate meat $\mathrm{pH}$. The obtained $\mathrm{pH}$ value of SP was comparable to those reviewed by Kondaiah \& Panda (1992) and Rizzi et al. (2007) but slightly lower than those shown by
Lakshani et al. (2016). It is worth noting that the pH of both broilers and spent hen breast samples in the study of Lakshani et al. (2016) were somewhat high. The increasing $\mathrm{pH}$ could likely be due to activity of amine/amide producing bacteria as the samples were collected from a local market without the information regarding manufacturing date.

In general, breast muscle of meat-type birds comprises a greater extent of fast-twitch glycolytic fibers when compared to that of layers (Aberle et al., 2001). The glycolytic fibers possess to rapid postmortem metabolic rate (Dransfield \& Sosnicki, 1999); thus, the lower ultimate $\mathrm{pH}$ in the fast-growing birds can be anticipated. However, in this study, the BR samples exhibited the greater degree of $\mathrm{pH}$ than that of SP corresponding to the growing numbers of recent reports pointing out the greater ultimate $\mathrm{pH}$ of the fastgrowing birds in comparison to that of slow-growing ones (Berri et al., 2007; Vaithiyanathan et al., 2008). This aberrantly high ultimate $\mathrm{pH}$ has been consistently observed among modern commercial broilers affected with an emerging defect, known as white striping abnormality (Mazzoni et al., 2015; Alnahhas et al., 2016; Malila et al., 2018). Such abnormal condition has been hypothesized to be a detrimental consequence of breeding selection for accelerated growth rate and enlarged breast muscle which triggers the imbalance between muscle fiber and vascularization (Kuttappan et al., 2013; Petracci et al., 2013). An exertion of the growth-induced myopathy on a decrease in protein functionality has been extensively observed (Petracci et al., 2013; Baldi et al., 2018), corresponding to the greater drip loss, cook loss and expressible water of BR over SP samples. The reduced protein functionality, particularly WHC, of the abnormal meat potentially attributed by protein denaturation (Mudalal et al., 2014) may explain the markedly increased alkalinesoluble protein fraction in the BR. On the other hand, neither white striping nor other quality abnormalities have been observed in breast meat of any spent hens.

Postmortem proteolytic activities of endogenous proteinases on target muscle proteins also play roles in meat tenderness (Kemp et al., 2010). As the structural proteins responsible for lateral and longitudinal integrity are degraded into fragments, the myofibrils tend to break more easily under force. By determining proteolytic capacity within breast muscle samples of 6-week-old chickens, Schreurs et al. (1995) indicated that White Leghorns showed the greater calpain activities but lower calpastatin activities compared to those of fast-growing broilers. As regards, the greater MFI value of SP samples was anticipated as the higher 
the proteolytic rate could bring about the rupture of myofibrils into fragments to the greater extent (Taylor et al., 1995). However, the current observation exhibited the opposite trend. The MFI of the SP samples was approximately 3.5-fold lower than that of the BR, indicating that the $\mathrm{BR}$ proteins were fragmented to the greater extent in comparison to that of SP, which was consistent with large variation of NPN fraction in the BR. The contradiction could be the effect of animal age as declined activities of $\mu$ - and $m$-calpains in turkey breast muscle were observed when slaughter age of the turkeys was extended from 5 weeks to 9 weeks (Northcutt et al., 1998). Another possibility could be related with development of white striping condition within the fast-growing broilers. Increased degree of fiber degradation, resulting in small protein fragments, has been observed within the breast showing white striping condition (Mudalal et al., 2014).

Thermal behaviors of BR and SP samples were consistent with ones of raw breast meat previously reported (Kijowski \& Mast, 1988; Fernández-Martín et al., 2000; Kuo et al., 2005). It is interesting to observe that, in the SP samples, the first and the last denaturation temperatures $\left(55.1^{\circ} \mathrm{C}\right.$ and $77.7^{\circ} \mathrm{C}$, respectively) were matched with the thermogram of water-washed myofibrils reported in the study of Kijowski \& Mast (1988). On the other hand, the first peak of the BR samples was consistent with the denaturation temperature of isolated myosin. The current DSC results supported the superior myofibril integrity of SP meat while the myofibrils of the BR might undergo fragmentation to the greater extent, resulting in increasing free myosin molecules in the meat. The fifth transition is usually associated with denaturation of actin (Kijowski \& Mast, 1988). The significantly greater $\Delta \mathrm{H}$ of such peak in the SP samples suggested that the actin in SP samples might denature to the lesser extent in comparison to that of the BR, corresponding with a lower alkali-soluble protein fraction observed in the SP. The peak transition temperature of connective tissues previously reported was varied between $59^{\circ} \mathrm{C}$ to $70^{\circ} \mathrm{C}$, depending on the ratio between endomysium to perimysium, structure and heating rate (Purslow, 2018). Herein, the broad thermal change around $62.1^{\circ} \mathrm{C}$ accompanied with the absence of the peak at $67.6^{\circ} \mathrm{C}$ in the SP may imply interactions of the connective tissue either at intra- or inter-molecular levels, supporting heat stability of the SP connective tissue. Fernández-Martín et al. (2000) also observed multiple endothermic transitions with a slight shift toward higher temperature of chicken breast meat.
In conclusion, the present study suggested the tough texture of the cooked spent Lohmann breast meat was associated with the high total and heat-stable collagen content accompanied with dense organization of small muscle fibers and the less postmortem degradation of myofibril integrity. Since collagen generally provides background toughness to the meat, tenderization of the spent Lohmann meat could potentially be achieved by disrupting myofibril structure while preserving meat protein functionality, particularly WHC. The process of disintegrating muscle fibers without disturbing water retention in Lohmann breast meat are under investigation. The success of this findings could lay foundation in preparing the whole-muscle products from spent Lohmann fowls; hence, utilization of the spent hens could be maximized.

\section{ACKNOWLEDGEMENTS}

The authors are grateful for chicken samples from Sun Food International Company, Ltd. and experimental facilities at Food Biotechnology Research Unit, BIOTEC (Thailand). This research was financially supported by Young Scientist and Technologist Program (YSTP, grant number YSTP: SP58-824), National Science and Technology Development Agency (Thailand) to YM, SI and $\mathrm{KL}$.

\section{REFERENCES}

Aberle ED, Forrest JC, Gerrard DE, Mills EW. Principles of meat science. $4^{\text {th }}$ ed. lowa: Kendall/Hunt Publishing Company; 2001

Alnahhas N, Berri C, Chabault M, Chartrin P, Boulay M, Bourin MC, et al. Genetic parameters of white striping in relation to body weight, carcass composition, and meat quality traits in two broiler lines divergently selected for the ultimate $\mathrm{pH}$ of the pectoralis major muscle. BMC Genetics 2016;17:61

Alves MFR, Abe FR, Boleli IC. Influence of enclosure size on growth of breast and leg muscle fibers in domestic fowl. International Journal of Poultry Science 2012;11:361-367.

An JY, Zheng JX, Li JY, Zeng D, Qu LJ, Xu GY, et al. Effect of myofiber characteristics and thickness of perimysium and endomysium on meat tenderness of chickens. Poultry Science 2010;89:1750-1754.

AOAC - Association of Official Analytical Chemists. Official methods of analysis of association of official analytical chemists. Gaithersburg: AOAC International; 2000.

Baldi G, Soglia F, Mazzoni M, Sirri F, Canonico L, Babini E, et al. Implications of white striping and spaghetti meat abnormalities on meat quality and histological features in broilers. Animal 2018;12:164-173.

Berri C, Le Bihan-Duval E, Debut M, Santé-Lhoutellier V, Baéza E, Gigaud $V$, Jégo $Y$, Duclos MJ. Consequence of muscle hypertrophy on characteristics of Pectoralis major muscle and breast meat quality of broiler chickens. Journal of Animal Science 2007:85:2005-2011.

Buzala M, Janicki B. Review: effects of different growth rates in broiler breeder and layer hens on some productive traits. Poultry Science 2016;95:2151-2159. 
Chen Y, Qiao Y, Xiao Y, Chen H, Zhao L, Huang M, et al. Differences in physicochemical and nutritional properties of breast and thigh meat from crossbred chickens, commercial broilers, and spent hens. AsianAustralasian Journal of Animal Science 2016;29:855-864.

Chuaynukool K, Wattanachant S, Siripongvutikorn S. Chemical and physical properties of raw and cooked spent hen, broiler and Thai indigenous chicken muscles in mixed herbs acidified soup (Tom Yum). Journal of Food Technology 2007;5:180-186.

Chueachuaychoo A, Wattanachant S, Benjakul S. Quality characteristics of raw and cooked spent hen Pectoralis major muscles during chilled storage: Effect of salt and phosphate. International Food Research Journal 2011;18:601-613.

Cooke VE, Gilpin S, Mahon M, Sandercock DA, Mitchell MA. A comparison of skeletal muscle fibre growth in broiler and layer chickens. British Poultry Science 2003;44:S33-34.

Dawson PL, Sheldon BW, Miles JJ. Effect of aseptic processing on the texture of chicken meat. Poultry Science 1991;70:2359-2367.

DeVitre HA, Cunningham FE. Tenderization of spent-hen muscle using papain, bromelin, or ficin alone and in combination with salts. Poultry Science 1985;64:1476-1483.

Dransfield E, Sosnicki AA. Relationship between muscle growth and poultry meat quality. Poultry Science 1999;78:43-746.

Fernández-Martín F, Fernández P, Carballo J, Jiménez-Colmenero F. DSC study on the influence of meat source, salt and fat levels, and processing parameters on batters pressurisation. European Food Research and Technology 2000;211:387-392.

Fletcher DL. Poultry meat quality. World's Poultry Science Journal 2002;58:131-145.

Funaro A, Cardenia V, Petracci M, Rimini S, Rodriguez-Estrada MT, Cavani C. Comparison of meat quality characteristics and oxidative stability between conventional and free-range chickens. Poultry Science 2014;93:1511-1522.

Hopkins DL, Littlefield PJ, Thompson JM. A research note on factors affecting the determination of myofibrillar fragmentation. Meat Science 2000;56:19-22.

Jaturasitha S, Srikanchai T, Kreuzer M, Wicke M. Differences in carcass and meat characteristics between chicken indigenous to northern Thailand (Black-Boned and Thai native) and imported extensive breeds (Bresse and Rhode Island Red). Poultry Science 2008;87:160-169.

Jin SK, Kim IS, Jung HJ, Kim DH, Choi YJ, Hur SJ. The development of sausages including meat from spent laying hen surimi. Poultry Science 2007; $86: 2676-2684$

Johnston IA, Alderson R, Sandham C, Dingwall A, Mitchell D, Selkirk C, et al. Muscle fibre density in relation to the colour and texture of smoked Atlantic salmon (Salmo salar L.). Aquaculture 2000;189:335-349.

Kang GH, Kim SH, Kim JH, Kang HK, Kim DW, Seong PN, et al. Effect of Flammulinavelutipes on spent-hen breast meat tenderization. Poultry Science 2012;91:232-236.

Kemp CM, Sensky PL, Bardsley RG, Buttery PJ, Parr T. Tenderness-an enzymatic view. Meat Science 2010;84:248-256.

Kijowski JM, Mast MG. Thermal properties of proteins in chicken broiler tissues. Journal of Food Science 1988;53:363-366.

Kittiphattanabawon P, Benjakul S, Visessanguan W. Isolation and characterization of collagen from the cartilages of brownbanded bamboo shark (Chiloscyllium punctatum) and blacktip shark (Carcharhinus limbatus). LWT - Food Science and Technology 2010;43:792-800.
Kondaiah N, Panda B. Processing and utilization of spent hens. World's Poultry Science Journal 1992;48:255-268.

Koomkrong A, Theerawatanasirikul S, Boonkaewwan C, Jaturasitha S, Kayan A. Breed-related number and size of muscle fibres and their response to carcass quality in chickens. Italian Journal of Animal Science 2015;14:638-642.

Kuo HL, Chen MT, Liu DC, Lin LC. Relationship between thermal properties of muscle proteins and pork quality. Asian-Australasian Journal of Animal Science 2005;18:427-432.

Kuttappan VA, Shivaprasad HI, Shaw DP, Valentine BA, Hargis BM, Clark $\mathrm{FD}$, et al. Pathological changes associated with white striping in broiler breast muscles. Poultry Science 2013;92:331-338.

Lakshani P, Jayasena DD, Jo C. Comparison of quality traits of breast meat from commercial broilers and spent hens in Sri Lanka. Korean Journal of Poultry Science 2016;43:55-61.

Lin CY, Hsu JC. Effects of surgical caponization of growth performance, fiber diameter and some physical properties of muscles in Taiwan country chicken cockerels. Asian-Australasian Journal of Animal Sciences 2002;15:401-405.

Mangiafico SS. An R companion for the handbook of biological statistics. Version 1.3.3 [cited 2017 Nov 1].. New Brunswick: Rutgers Cooperative Extension; 2015 Available from: https://rcompanion.org/ rcompanion/d_02.html.

Malila $Y$, U-chupaj J, Srimarut $Y$, Chaiwiwattrakul P, Uengwetwanit $T$, Arayamethakorn $\mathrm{S}$, et al. Monitoring of white striping and wooden breast cases and impacts on quality of breast meat collected from commercial broilers (Gallus gallus). Asian-Australasian Journal of Animal Science 2018:31:1807-1817.

Mazzoni M, Petracci M, Meluzzi A, Cavani C, Clavenzani P, Sirri F Relationship between pectoralis major muscle histology and quality traits of chicken meat. Poultry Science 2015;94:123-130.

Mudalal S, Babini E, Cavani C Petracci M. Quantity and functionality of protein fractions in chicken breast fillets affected by white striping. Poultry Science 2014;93:2108-2116.

Mutungi G, Purslow P, Warkup C. Influence of temperature, fibre diameter and conditioning on the mechanical properties of single muscle fibres extended to fracture. Journal of Science and Food Agriculture 1996:72:359-366.

Northcutt JK, Pringle TD, Dickens JA, Buhr RJ, Young LL. Effects of age and tissue type on the calpain proteolytic system in turkey skeletal muscle. Poultry Science 1998;77:367-372.

Petracci M, Mudalal S, Bonfiglio A, Cavani C. Occurrence of white striping under commercial conditions and its impact on breast meat quality in broiler chickens. Poultry Science 2013;92:1670-5.

Purslow PP. Intramuscular connective tissue and its role in meat quality. Meat Science 2005;70:435-447.

Purslow PP. Contribution of collagen and connective tissue to cooked meat toughness;some paradigms reviewed. Meat Science 2018;144:127134.

Rizzi C, Marangon A, Chiericato GM. Effect of genotype on slaughtering performance and meat physical and sensory characteristics of organic laying hens. Poultry Science 2007;86:128-135.

Sams AR. Lathyrogen effects of the collagen heat stability and tenderness of spent fowl muscle. Poultry Science 1990;69:477-481.

Schreurs FJG, Van Der Heide D, Leenstra FR, De Wit W. Endogenous proteolytic enzymes in chicken muscles. Difference among strains with different growth rate and protein efficiencies. Poultry Science 1995;74:523-537. 
Sirri F, Castellini C, Bianchi M, Petracci M, Meluzzi A, Franchini A. Effect of fast-, medium- and slow-growing strains on meat quality of chickens reared under the organic farming method. Animal 2011;5:312-319.

Smith-Mungo LI, Kagan HM. Lysyl oxidase: properties, regulation and multiple functions in biology. Matrix Biology 1998;16:387-398.

Snedeker JG, Gautieri A. The role of collagen crosslinks in ageing and diabetes - the good, the bad, and the ugly. Muscles, Ligaments and Tendons Journal 2014;4:303-308.

Sorapukdee S, Uesakulrungrueng C, Pilasombut K. Effects of humectant and roasting on physicochemical and sensory properties of jerky made from spent hen meat. Korean Journal for Food Science of Animal Resources 2016;36:326-334.

Suriani NW, Purnomo H, Estiasih T, Suwetja IK. Physicochemical properties, fatty acids profile and cholesterol content of indigenous manado chicken, broiler and spent hen meat. International Journal of ChemTech Research 2014;6:3896-3902.

Tang H, Gong YZ, Wu CX, Jiang J, Wang Y, Li K. Variation of meat quality traits among five genotypes of chicken. Poultry Science 2009;88:22122218.
Taylor RG, Geesink GH, Thompson VF, Koohmaraie M, Goll DE. Is Z-disk degradation responsible for postmortem tenderization?. Journal of Animal Science 1995;73:1351-1367.

Tyszkiewicz I, Kłossowska BM, Wieczorek U, Jakubiec-Puka A. Mechanical tenderisation of pork meat: protein and water release due to tissue damage. Journal of the Science of Food and Agriculture 1997;73:179185.

U-chupaj J, Malila Y, Gamonpilas C, Kijroongrojana K, Petracci M, Benjakul $\mathrm{S}$, et al. Differences in textural properties of cooked caponized and broiler chicken breast meat. Poultry Science 2017;96:2491-2500.

Vaithiyanathan S, Naveena BM, Muthukumar M, Girish PS, Ramakrishna C, Sen $A R$, et al. Biochemical and physicochemical changes in spent-hen meat during postmortem aging. Poultry Science 2008;87:180-186.

Visessanguan W, Benjakul S, Riebroyb S, Thepkasikul P. Changes in composition and functional properties of proteins and their contributions to Nham characteristics. Meat Science 2004;66:579-588.

Visessanguan W, Ogawa M, Nakai S, An H. physicochemical changes and mechanism of heat-induced gelation of arrow tooth flounder myosin. Journal of Agricultural and Food Chemistry 2000;48:1016-1023. 
